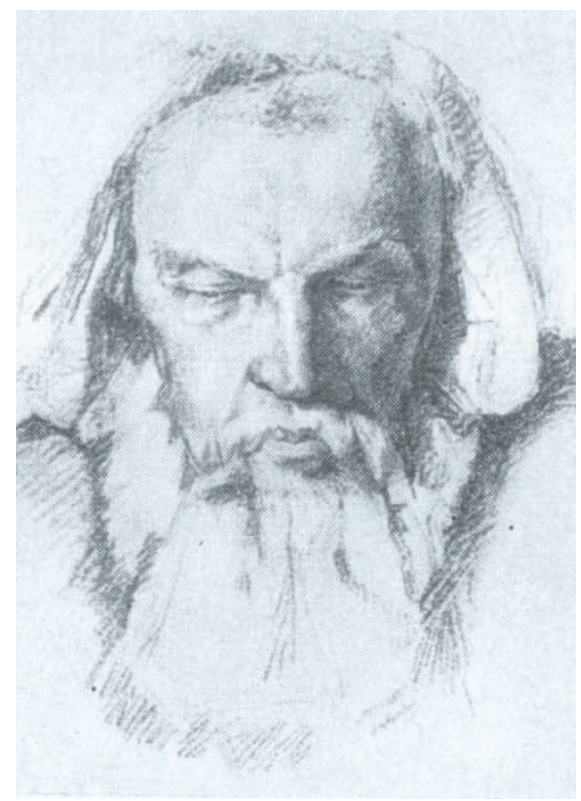

Dmitrii Mendeleev's periodic table was in tune with imperial Russia's desire for social order.

creation of the periodic system, so Gordin might have done well to give more attention to Mendeleev's textbooks. His 1861 organicchemistry textbook is dealt with too hastily, with the excuse that it was quickly eclipsed by Aleksandr Butlerov's book. And Mendeleev's successful Principles of Chemistry could have been analysed against the background of the tradition of university textbooks. Gordin also provides no details about earlier attempts at classification, or about how the periodic system was received either in Russia or abroad.

But the history of chemistry is not Gordin's main focus. Instead he attempts to understand the cultural impact of the major reforms and political upheavals that occurred in imperial Russia before the end of the nineteenth century. From this perspective, Mendeleev's periodic system appears as a metaphor underlying a programme for restructuring and modernizing tsarist Russia. The periodic law, with its predictions of unknown elements and bold corrections of atomic weights, was one expression of an irrepressible attempt to eradicate misfits and anomalies in various domains.

This long-standing quest for order contrasts with Mendeleev's versatility. Although for today's chemists he embodies the chemistry of the elements, he did not spend much time on this topic. He abandoned his research on elements soon after constructing the periodic table, despite uncertainties about the classification of rare-earth elements and rare gases. In the 1870s he initiated a project that was his age's equivalent of 'big science' because it involved high-pressure devices. His objective was to investigate deviations from the ideal gas law with the expectation of isolating ether, an unknown, all-pervading substance that was postulated by both Newton's dynamics and James Clerk Maxwell's electromagnetism. Mendeleev's ambition was to integrate ether as a chemical element within the periodic system, in order to unify the natural sciences. He also sought to save the individuality and integrity of chemical elements, which were threatened by radioactivity and electrons - the existence of subatomic particles favoured the view that atomic elements were made up of smaller units.

In the name of science, Mendeleev spent his life fighting against 'deviations' or superstitions. For example, he struggled against the fashion among educated people for spiritualism, and set up a commission for investigating mediums at the Russian Physical Society. Mendeleev was also concerned with the public face of science. In the newspapers and in his books, Mendeleev defended the legitimacy and the authority of scientific societies in matters of public opinion. $\mathrm{He}$ acted as an expert, first locally and then at the national level, notably through his work on standardization at the Bureau of Weights and Measures and in his attempt to modernize the calendar.

Gordin portrays Mendeleev as a loyal subject of the Tsar, with conservative ideals, who fought desperately against the disintegration both of the Russian Empire and of chemical elements. He never really separated in his mind the future of Russia from the future of science, and had ambitions to be the Russian Newton.

This highly readable book offers two important lessons for working scientists. First, Mendeleev's career illustrates the interplay between scientific creation and economic, political and educational projects. Second, it may be a consolation to know that such a well known scientist endured an incredible number of failures throughout his life. Notably, his project to isolate ether failed and affected his scientific credibility. His solution theory and his views about the origin of oil were wrong. He also failed to reform the calendar, and his application to the Imperial Academy in St Petersburg was turned down. But above all, his firm belief in the individuality of chemical elements - the firm ground in which the periodic system was rooted - finally crumbled.

Bernadette Bensaude-Vincent is in the Department of Philosophy, Université de Paris X, 92001 Nanterre Cedex, France.

\title{
An architectural aside
}

The Italian scientific revolution, championed by Galileo in the seventeenth century, shares its roots with the mathematical beauty of Renaissance architecture. Galileo, for example, found that studies by the sixteenth-century master architects Giorgio Vasari and Michelangelo came in handy for computing the height of mountains on the Moon. And the Roman architect Marcus Vitruvius Pollio - whose Ten Books on Architecture (De architectura) is still required reading for architecture students today - drew on the proportions of the human body to scale his buildings, on astronomy for their accurate orientation with respect to the heavens, and, of course, on geometry.

The extensive margins of the first printed version (incunabulum) of the Ten Books on Architecture, in 1486, allowed for hand-written annotations. In 1520, Giovanni Battista Sangallo, a leading figure of sixteenth-century Roman architecture who worked with Raphael on St Peter's Basilica in Rome, filled the margin with annotations and beautiful drawings.

To celebrate its 400th anniversary last year, the Accademia Nazionale dei Lincei, Italy's national academy, has published a high-quality facsimile of this copy of Ten Books on Architecture.The page shown here describes the importance of the orientation of buildings for the health of their inhabitants. In a series of illustrated comments, Sangallo stresses the relevance of this for the Roman climate.

This exquisite book links the genius of
Vitruvius' original text to its first printed edition, to the freshness of Sangallo's notes, and to a contemporary introduction by art historian Ingrid Rowland.

Giovanni F. Bignami

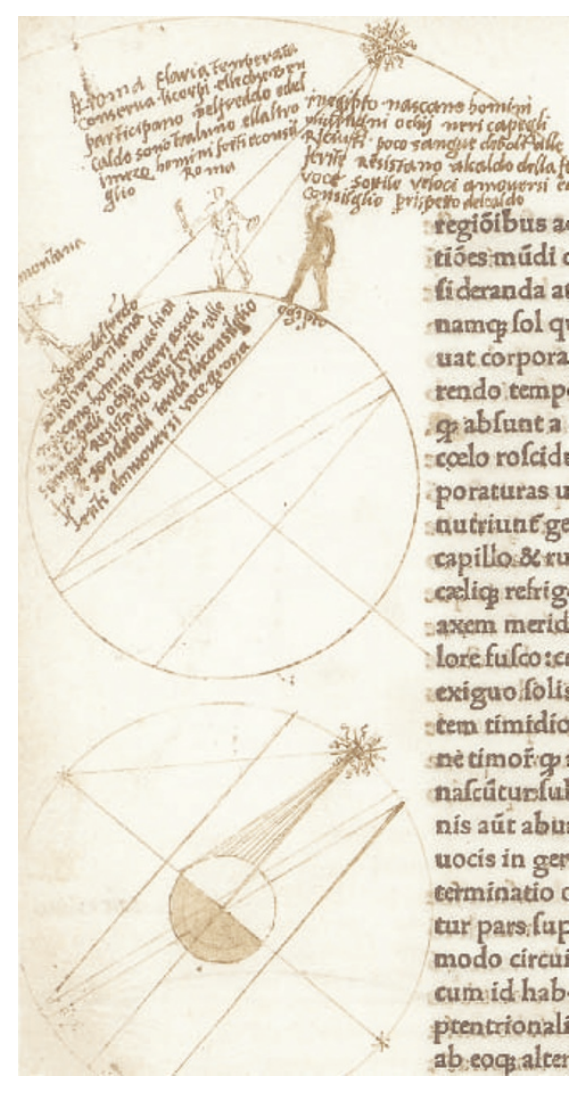

